\title{
Fellowship training in critical care ultrasound
}

\author{
Brian Buchanan, BSc (Hon), MD, FRCPC • Hailey Hobbs, BSc (Hon), MD, FRCPC • \\ Robert Arntfield, BSc, MD, FRCPC
}

Received: 29 December 2017/Revised: 29 January 2018/Accepted: 1 February 2018/Published online: 13 February 2018

(c) Canadian Anesthesiologists' Society 2018

\section{To the Editor,}

Critical care ultrasound (CCUS) comprises techniques commonly used by the intensive care physician including critical care echocardiography and general critical care ultrasonography (lungs, abdomen, deep vein thrombosis assessment, and procedural guidance). Mounting evidence validates the ability of CCUS to improve patient-centred outcomes including reductions in procedural complications and mortality. ${ }^{1}$ Furthermore, CCUS improves diagnostic accuracy and has comparable, if not superior, performance to traditional diagnostic modalities. ${ }^{2}$ Critical care ultrasound is non-invasive, repeatable, reduces costs, and has strong inter-user reliability. For these reasons, it has been endorsed as a core skill by 12 critical care societies worldwide, including Canada. ${ }^{3}$

Despite the framework offered by training guidelines from Canada, the United States, and on an international level, ${ }^{3}$ organized CCUS education in North America is lacking. ${ }^{4}$ The greatest barrier to training in CCUS today is the scarcity of experienced faculty to take on the nontrivial training and administrative requirements associated with program-level CCUS training. ${ }^{4}$

B. Buchanan, BSc (Hon), MD, FRCPC ( $\square)$

Department of Critical Care Medicine, University of Alberta, Edmonton, AB, Canada

e-mail: brian.buchanan24@gmail.com

H. Hobbs, BSc (Hon), MD, FRCPC .

R. Arntfield, BSc, MD, FRCPC

Department of Adult Critical Care Medicine, London Health

Sciences Centre - Victoria Hospital, Western University,

London, ON, Canada
A specialty-wide shortage of skilled leaders in ultrasound is not a novel problem. As the earliest adopters of point-of-care ultrasound, emergency medicine (EM) long ago reached the crossroads we in critical care currently face. The EM community embraced postgraduate fellowship training and, since the mid-1990s, EM point-of-care ultrasound fellowships have produced leaders in ultrasound who, in addition to being competent at wielding a transducer, are steeped in the other nonclinical skills needed to implement ultrasound training and curricula. As CCUS is now firmly established within the milieu of critical care medicine, we submit that CCUS fellowship programs will be required to meet the demand for training from fellows in critical care medicine (CCM) and to satisfy society-level encouragement of its uptake. A CCUS fellowship also offers a sound platform for advancement of research into CCUS.

On this basis, Western University has developed the first CCUS fellowship. The impetus of our fellowship program arose organically from the recognized need to groom future faculty and national leadership in the expanding subspecialty of CCUS. We designed broad professional competencies by amalgamating the suggestions from EM literature and CCUS consensus recommendations, shown in the Table. Technical proficiency, educational leadership, quality assurance, administration, and research form the cornerstones of the program.

Educational, academic, and administrative leadership is vital to the instantiation of a CCUS program. Indeed, a single expertly trained individual carried the Western University program from conception through to curriculum design, resource development, workshop implementation, integration of quality assurance, and initiation of a formal CCUS rotation. With 40 senior residents per year completing dedicated rotations in CCUS, and nearly 4000 


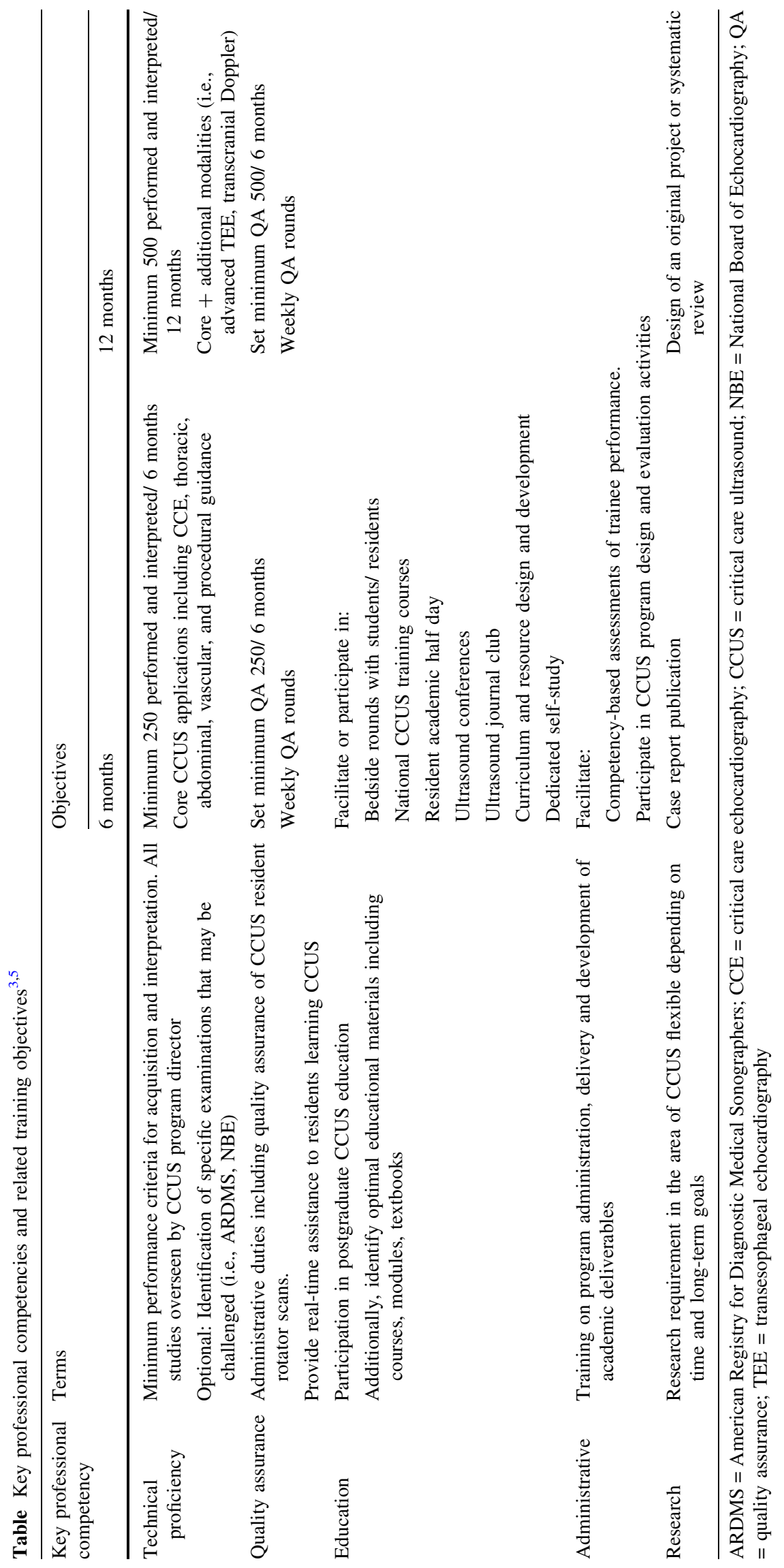


CCUS studies archived and over-read each year, Western University's intensive care unit offers a unique environment in North America for CCUS training and dissemination. ${ }^{5}$

Our proposed fellowship model could accommodate either six or 12 months' duration of training, with 12 months permitting a larger variety and volume of ultrasound studies. Our CCUS fellowship will equip its graduates to perform CCUS expertly themselves, lead scholarly work, and, eventually, complete the pedagogical lifecycle and establish CCUS training and fellowship programs at other sites. Although CCM is most prepared to take advantage of this fellowship and was the original intent, consideration is made for other specialties, where interest and need for ultrasound champions are greatest, including internal medicine and anesthesia.

As other specialties such as internal medicine, anesthesiology, general surgery, and hospital medicine begin seeking similar ultrasound training, how we in critical care address our training needs will be followed closely. A dialogue between CCUS experts and educational stakeholders may promote consensus and the subsequent formation of CCUS fellowship standards. Through such fellowships, we may finally meet the standard of CCUS training that worldwide critical care societies established nearly ten years ago.
Conflicts of interest None declared.

Disclosures Dr. Arntfield is an educational consultant for Fujifilm Sonosite, Inc.

Editorial responsibility This submission was handled by Dr. Gregory L. Bryson, Deputy Editor-in-Chief, Canadian Journal of Anesthesia.

\section{References}

1. Kanji HD, McCallum J, Sirounis D, MacRedmond R, Moss $R$, Boyd $J H$. Limited echocardiography-guided therapy in subacute shock is associated with change in management and improved outcomes. J Crit Care 2014; 29: 700-5.

2. Lichtenstein D, Goldstein I, Mourgeon E, Cluzel P, Grenier P, Rouby JJ. Comparative diagnostic performances of auscultation, chest radiography, and lung ultrasonography in acute respiratory distress syndrome. Anesthesiology 2004; 100: 9-15.

3. Arntfield $R$, Millington $S$, Ainsworth $C$, et al. Canadian recommendations for critical care ultrasound training and competency. Can Respir J 2014; 21: 341-5.

4. Mosier JM, Malo J, Stolz LA, et al. Critical care ultrasound training: a survey of US fellowship directors. J Crit Care 2014; 29 : 645-9.

5. Arntfield RT. The Utility of remote supervision with feedback as a method to deliver high-volume critical care ultrasound training. J Crit Care 2015; 30: 441.e1-6. 